Удк 343.35

\title{
Л.М. Прозументов
}

\section{УГОЛОВНО-ПРАВОВОЕ ПРОТИВОДЕЙСТВИЕ КОРРУПЦИИ В РОССИИ: ИСТОРИЯ И СОВРЕМЕННОЕ СОСТОЯНИЕ}

\begin{abstract}
В статье содержится краткий анализ некоторых подходов российского законодательства к противодействию коррупции. Отмечается, что на протяжении многих лет законодатель пытался противодействовать коррупции через определение конкретных форм коррупционного поведения и их закрепление в уголовном праве: мздоимство, посул, лихоимство, подлог, поборы с населения при сборе податей, вымогательство и т.п. Такой подход к коррупционному поведению характерен и для современного российского уголовного права. В статье предлагается изменить существующий подход. Утверждается, что наиболее эффективно противодействовать коррупции можно лишь используя весь комплекс российского законодательства.

Ключевые слова: закон; поведение; преступление; коррупция; уголовное право; общественная опасность.
\end{abstract}

На протяжении пути развития человечества проблема коррупции препятствовала развитию государственности.

Первое упоминание о коррупции относится ко второй половине XXIV в. до нашей эры. Как следует из расшифрованных клинописей древнего Вавилона, перед шумерским царем Урукагином весьма остро стояла проблема пресечения злоупотреблений судей и чиновников, вымогавших незаконные вознаграждения. Правитель устраивал показательные и жестокие наказания за подобное поведение, но даже это не приводило к желаемым результатом. Взятки носили массовый характер [1. С. 272-273].

Во время археологических раскопок, проведенных в Пакистане, учеными были обнаружены документы, свидетельствующие о массовых проявлениях коррупции в Иерусалиме в период после вавилонского пленения евреев в 597-538 гг. до нашей эры.

Министр Бхараты под псевдонимом Каутилья опубликовал сборник законов «Артхашастра». Данный документ является первым в истории законом, направленным на противодействие коррупции. С этой проблемой сталкивались и правители Древнего Египта [2].

Тематика коррупции встречается и в различных религиозных документах. В первую очередь речь в них идет о судьях. Так, в Книге премудрости Иисуса сына Сирахова отец наставляет сына: «...не лицемерь перед устами других и будь внимателен к устам твоим... Да не будет рука твоя распростерта к принятию... Не делай зла, и тебя не постигнет зло; удаляйся от неправды и она уклониться от тебя... Не домогайся сделаться судьею, чтобы оказаться бессильным сокрушить неправду, чтобы не убояться когда-либо лица сильного и не положить тени на правоту твою...» [3. С. 644]. Из данного наставления следует, что библейскому обществу были известны факты подкупа судей и осуществления нечестного правосудия.

Расцвет коррупции исследователи относят к эпохе упадка Античности, когда появились такие государственные чиновники, о которых говорили: «Он приехал бедным в богатую провинцию, а уехал богатым из бедной провинции». В это время в римском праве появился специальный термин «сorrumpire», который был синонимом слов «портить», «подкупать» и служил для обозначения любых должностных злоупотреблений. Отметим, что одной из причин распада Римской империи явилось огромное, разрушительное влияние коррупции.
Формирование и развитие коррупции в России имеет многовековую историю. По сохранившимся записям летописцев, взятки появились еще в Древней Руси, и сразу же с ними стали решительно бороться. Так, митрополит Кирилл, осуждал мздоимство наряду с пьянством и колдовством, за что и настаивал карать соответствующе, т.е. смертной казнью. В соответствии с положением, закрепленным в Русской Правде: «Аще жена зелейница, чародеица. Наузница - её - казнить» [4. С. 191].

Первое письменное упоминание о посулах как о незаконном вознаграждении княжеским наместникам за осуществление официально властных полномочий относится к концу XIV в. Соответствующая норма была закреплена в Двинской уставной грамоте (1397 г.). В последующем в новой редакции Псковской Судной грамоты понятие «посула» употребляется в смысле взятки [5. С. 180-231; 6].

B XV в. коррупция на Руси приобрела характер системы. Чиновники выполняли свои прямые обязанности только за подношение. Такие деяния именовались «мздоимство» и воспринимались как норма. К «лихоимству» относился подкуп должностных лиц для совершения чего-то незаконного, что было возможно только благодаря должности. Отметим, что уже в то время были попытки побороть лихоимство. Первый закон о наказании судей за взятку содержится в Судебнике 1497 г. [7. С. 54]. Спустя полвека в Судебнике 1550 г. вопрос взяточничества стал рассматриваться более детально. В соответствии с Судебником «для дьяка, который за взятку составил подложный протокол или исказил показания сторон, было предусмотрено наказание в виде тюремного заключения. Кроме того, он должен был выплатить штраф в размере суммы иска» [8. С. 97].

В последующем Иваном Грозным была впервые введена смертная казнь в качестве наказания за чрезмерность во взятках.

C XVI в. возникло новое проявление взяточничества - вымогательство. Глава Земского приказа Леонтий Плещеев при царе Алексее Михайловиче Романове превратил суд в преступный орган, занимавшийся вымогательством. Судебные дела решались по принципу «кто больше даст, тот выиграет». Петр Траханитов, ведавший Пушкарским приказом, месяцами не выплачивал жалованье стрельцам, оружейникам и другим подчиненным, присваивая деньги и выигрывая суды. Народ был доведен до отчаяния и 25 мая 1648 г. поднял в Москве бунт. Царю Алексею Михайловичу пога- 
сить восстание не удалось, и он был вынужден выдать сначала Плещеева (которого толпа растерзала), а затем казнить Траханитова. Бунт оказался первым в российской истории народным выступлением против коррупции. Впоследствии было принято Соборное уложение 1649 г., которое предусматривало многочисленные наказания за преступления, подпадавшие под понятие коррупции: утайку пошлин при регистрации дел, притеснение населения, подлог при переписке судебного дела и др. [9. С. 47, 140].

Из сказанного следует, что в XVII в. происходит трансформация подношений и мздоимства. В России в это время наиболее распространены были следующие формы коррупционного поведения: почести, оплата услуг и посулы. Уважительное значение «почести» проявляется и в русском обычае одаривать уважаемого человека, и в особенности высокое начальство хлебом-солью. Но уже в XVII в. «почесть» всё больше приобретала значение разрешенной взятки. Другая форма подношений чиновникам связана с расходом на ведение и оформление дел. Доходы чиновников в виде оплаты на ведение и оформление дел учитывались при определении им жалованья: если в приказе было много дел, с которых можно было «кормиться», то им платили меньше жалование. То есть практика «кормления от дел» была частью государственной системы содержания чиновничества.

Третья форма коррупционного поведения именовалась «посулы».

Посулы - это плата за благоприятное решение дел, за совершение незаконных деяний. Чаще всего «посулы» выражались в переплатах за услуги, за ведение и оформление дел, и поэтому граница между двумя формами коррупционного поведения была размытой и едва различимой [10. С. 210].

В XVIII в. институт «кормления» был признан пагубным. В царствование Петра I впервые было осознано, что коррупция является злом для государства, подрывает его бюджет и разлагает общество. Проведя губернскую реформу 1708 г., Петр I организовал государственную службу за жалованье. Следует отметить, что Указ Петра I «О воспрещении взяток и посулов», в котором взяточничество квалифицировалось как преступление, подлежащее строгому наказанию, имел большое значение для России [11. С. 749].

На протяжении XVIII в. круг коррупционных преступлений расширялся. К взяткам стали приравниваться поборы с населения при сборе податей, принесении присяги, оформлении документов, вымогательство, подлог.

В XIX в. коррупция превратилась в механизм государственного управления, что нашло отражение в законодательстве вообще и уголовном законодательстве в частности.

Уложение о наказаниях уголовных и исправительных 1845 г. содержало нормы, предусматривавшие уголовную ответственность за взяточничество, поборы с населения, вымогательство и т.д.

Наказание за перечисленные выше деяния содержалось и в Уголовном уложении 1903 г.

С установлением советской власти проблема противодействия коррупции осталась. Не случайно од- ними из первых декретов новой власти были Декрет «О взяточничестве» (8 мая 1918 г.) и Декрет «О борьбе со взяточничеством».

В уголовных кодексах РСФСР 1922, 1926, 1960 гг. предусматривалась ответственность за дачу взятки, получение взятки, злоупотребление властью и служебными полномочиями, под которым понималось умышленное использование должностным лицом служебного положения вопреки интересам службы, если оно совершено из корыстной или иной личной заинтересованности и причинило существенный вред государственным или общественным интересам либо охраняемым законом правам и интересам граждан.

Являются ли данные общественно опасные деяния формами коррупционной деятельности? Безусловно. Однако эти формы нельзя считать исчерпывающими для определения коррупции, поскольку сама жизнь показывала существование и других форм коррупционной деятельности, не нашедших закрепления в нормах уголовного законодательства.

Особенно отчетливо это проявилось в конце 1970-х начале 1980-х гг., когда в СССР - в его республиках, областях, городах - расследовались сотни уголовных дел в отношении разного уровня государственных чиновников. Нередко их общественно опасная деятельность не вписывалась в существовавшее в то время уголовное законодательство, в частности в нормы, предусматривавшие уголовную ответственность за должностные преступления. Уже в те годы было очевидно, что понимаемый многими исследователями подход к «коррупции» через «подкуп», «личную корыстную заинтересованность» является слишком узким и не способен отразить того реального многообразия форм коррупционного поведения, которое существовало на практике.

Тем не менее именно этот подход продолжал доминировать не только в научных исследованиях, но и в законодательстве. Можно предполагать, что сторонники этого подхода даже усилили свои позиции с началом социально-экономических и политических преобразований в России. Произошло это вследствие того, что сама концепция реформ, во-первых, была криминологически не обоснована и, во-вторых, несла в себе огромный криминальный потенциал. Один из разработчиков и активных участников, пытавшихся реализовать концепцию, Е. Гайдар следующим образом говорил о её сути: поскольку существующая партийногосударственная номенклатура сама власть не отдает, силой отнять эту власть не представлялось возможным, то власть можно было лишь выкупить [12. С. 143].

В этой связи отметим, что подкуп стал одним из основных средств преобразования социально-экономических и политических отношений в России. Вопервых, бывшей советской партийно-хозяйственной номенклатуре дали возможность приобрести разной величины «куски» бывшей государственной собственности. Во-вторых, реформаторами неоднократно делались заявления о том, что одним из резервов переустройства общества являются теневая экономика и теневые капиталы, которые в конце 80-х гг. в СССР вообще и РСФСР в частности были просто огромны- 
ми. Так, по данным ученых Экономического НИИ при Госплане СССР, теневой товарооборот составлял 7090 млрд руб. в год, а соответствующий показатель в сфере услуг - 14-16 млрд руб. (при годовом объеме официального оборота 45 млрд руб.). Видный американский экономист В.Г. Тремл полагал, что продукция теневого сектора советской экономики составляла не менее $30 \%$ ВВП страны и в нем было около 20\% всей рабочей силы, а уровень доходов каждого работника в теневом секторе экономики в 8-10 раз превышал средний уровень доходов работников, занятых в государственном секторе экономики.

По оценке В.В. Панкратова, каждый третий рубль, эмиссированный Госбанком, «крутился» в то время в сфере теневой экономики. И наконец, известный экономист А. Бунич весь теневой оборот оценивал в 100 150 млрд руб., что составляло 17-25\% национального дохода [13. С. 144]. Оценки разные, но не противоречивые. Они убедительно свидетельствуют о том, что теневая экономика являлась существенной частью экономической системы страны.

Практика показывает, что уже с середины 1970-х гг. львиная доля средств, вращавшихся в теневой экономике, являлась «общаковскими» средствами, т.е. криминальными. И именно эти средства активно использовались для подкупа государственных чиновников разного уровня. Однако даже известные всем факты связи преступного мира и государственных чиновников (вспомним «узбекские», «краснодарские», «ростовские», «соколовские» и другие уголовные дела) в лучшем случае замалчивались, в худшем - отрицались властью.

Отмеченная тенденция особенно усилилась в период распада СССР и в первые годы существования независимого Российского государства. Проведение экономических, социально-политических реформ в Российской Федерации выявило немало таких форм деятельности как государственных служащих, так и лиц, ими не являющихся, но осуществляющих управленческие функции, которые были общественно опасными, но не вписывались в рамки существовавшего уголовного законодательства.

В научной литературе в последние 20 лет можно было встретить различные определения коррупции. Так, в начале 90-х гг. прошлого века под коррупцией понималось стремление должностного лица к наживе, разложение аппарата, обладающего властными либо хозяйственными (распорядительными) полномочиями, превратившего подведомственные ему учреждения в источник личного обогащения, не гнушающегося контактами с общеуголовной преступностью, принимать на службу профессиональных преступников [13. С. 324-325].

Позднее она определялась как социальное явление, характеризующееся подкупом - продажностью государственных и иных служащих, и на этой основе корыстным использованием ими личных либо узкогрупповых полномочий, связанных с ним авторитета и возможностей [15. С. 501], как и «...социальное явление, заключающееся в разложении власти, когда государственные (муниципальные) служащие и иные лица, уполномоченные на выполнение государственных функций, используют свое служебное положе- ние, статус и авторитет занимаемой должности в корыстных целях для личного обогащения или в групповых интересах» [16. С. 5].

Отметим, что применительно к конкретным составам уголовно наказуемых деяний коррупция изначально рассматривалась, прежде всего, как «подкуп одних лиц другими» (Н.Ф. Кузнецова), т.е. по существу речь шла только о взяточничестве во всех его формах и разновидностях [17. С. 135]. Существовали и другие подходы, суть которых сводилась к тому, что коррупция представляла собой только так называемое организованное или систематическое взяточничество, причем должностные лица зачастую подкупались как бы «на корню» (так называемый тотальный подкуп) [18. С. 5-6]. Некоторые авторы включали в «состав» коррупции и другие преступления, например корыстное злоупотребление служебным положением (по УК РФ 1996 г. - должностными полномочиями), хищения (Г.Н. Борзенков) [19. С. 136]. Отмечалось, что «взятка является наиболее отличительным и характерным проявлением коррупции...» (Ю.И. Ляпунов) [20. С. 672]. Некоторые исследователи предлагали и сводное понятие коррупционных преступлений: «...предусмотренные уголовным законом общественно опасные деяния, субъектом которых являются должностные лица и которые совершаются посредством использования должностных полномочий из корыстных побуждений и в целях личного обогащения» [21. С. 67]. Исследователями особо подчеркивалась связь взяточничества в составе коррупции с потворством преступной и антисоциальной деятельности, причем не только отдельных лиц, но и организованных групп и объединений. Наконец, коррупция рассматривалась и как необходимый элемент организованной преступности [22. С. 9].

В документах $\mathrm{OOH}$ по международным проблемам противодействия коррупции отмечается, что «коррупция - это злоупотребление государственной властью для извлечения выгод в личных целях». Такое определение более четко отграничивает сферу, в которой возможно совершение коррупционных преступлений и правонарушений, а именно сферу осуществления государственной власти.

В ст. 2 Федерального закона «О борьбе с коррупцией», принятого 22 ноября 1995 г. Государственной думой и одобренного Советом Федерации, но отклоненного бывшим Президентом Российской Федерации Б.Н. Ельциным, содержалось следующее определение: «Под коррупцией... понимаются не предусмотренное законом принятия материальных и иных благ и преимуществ лицами, уполномоченными на выполнение государственных функций, или лицами, приравненными к ним, путем использования своего статуса и связанных с ним возможностей (продажность), а также подкуп указанных лиц путем противоправного предоставления им физическими и юридическими лицами этих благ и преимуществ».

В проекте Федерального закона «Основы антикоррупционной политики» под коррупцией предлагалось понимать «подкуп (получение или дача взятки), любое незаконное использование лицом своего публич- 
ного статуса, сопряженное с получением выгоды (имущества, услуг или льгот, в том числе неимущественного характера) как для себя, так и для своих близких вопреки законным интересам общества и государства, либо незаконное представление такой выгоды указанному лицу» [23. С. 87].

Представляется, что приведенные выше определения можно оценить в целом как достаточно удачные, особенно для своего времени, однако в них нечетко определялся субъект коррупции, были недостаточно конкретизированы ее проявления, относящиеся к сфере действия уголовного права, при этом без достаточных оснований коррупцией признавалась дача взятки, использовались оценочные, излишние эмоциональные категории, например, «продажность».

Кроме того, говоря о коррупции, необходимо учитывать, что коррупционный характер носит не только получение взятки (ст. 290 УК РФ), но и иные корыстные должностные преступления - злоупотребление должностными полномочиями (ст. 285 УК РФ), превышение должностных полномочий (ст. 286 УК РФ), служебный подлог (ст. 292 УК РФ). Очевидно, что наряду с этим коррупция включает в себя совершение не только уголовно наказуемых деяний, но и административных, гражданско-правовых, финансовых правонарушений.

С принятием 25 декабря 2008 г. Федерального закона № 27Э-Ф3 «О противодействии коррупции» ее понятие впервые в нашей стране получило свое закрепление на законодательном уровне [24].

Так, в соответствии со ст. 1 данного Федерального закона коррупцией является «злоупотребление служебным положением, дача взятки, получение взятки, злоупотребление полномочиями, коммерческий подкуп либо иное незаконное использование физическим лицом своего должностного положения вопреки законным интересам общества и государства в целях получения выгоды в виде денег, ценностей, имущества или услуг имущественного характера, иных имущественных прав для себя или третьих лиц, незаконное предоставление такой выгоды указанному лицу другими физическими лицами».

Представляется, что раскрытие данного понятия с использованием нескольких категорий, «заимствованных» из уголовного законодательства РФ, а затем объединенных через их «неправомерность», недопустимо.

Полагаем, что в связи с отсутствием до принятия вышеназванного Федерального закона правового понятия «коррупция» (как известно, его нет ни в Уголовном кодексе РФ, ни в других отраслях российского законодательства), не корректным представляется использованный выше подход. Необходимо было сформулировать понятие, которое бы содержало в себе все существенные признаки, наличие которых являлось бы основанием для признания того или иного деяния коррупционным.

На наш взгляд, законодатель без достаточных оснований отнес к числу проявлений коррупции злоупотребления полномочиями и коммерческий подкуп, являющимися преступлениями против интересов службы в коммерческих и иных организациях (Глава 23 Особенной части УК РФ, которая входит в раз- дел VIII «Преступления в сфере экономики»). Субъектами данных преступлений должностные лица быть не могут (таковыми, применительно к деяниям, предусмотренным ст. 201, ч. 3, 4 ст. 204 УК РФ, являются лица, выполняющие управленческие функции в коммерческих или иных организациях, а к деяниям, предусмотренным ч. 1, 2 ст. 204 УК РФ, - любые вменяемые лица, достигшие возраста уголовной ответственности). Представляется нецелесообразным причислять такого рода деяния к коррупции, поскольку это явление традиционно ассоциируется с продажностью государственного аппарата. В то же время в анализируемом определении отсутствует упоминание превышения должностных полномочий и служебного подлога, несмотря на то, что многие такие преступления имеют вполне очевидную коррупционную направленность. Полагаем, что и дача взятки «в чистом виде» не должна рассматриваться как коррупция, поскольку субъектом этого преступления может быть любое физическое лицо. Из определения коррупции следует, что по своей сути данное явление предполагает, прежде всего, незаконное использование физическим лицом именно своего должностного положения. При этом очевидно, что дача взятки, безусловно, очень близко связана с коррупцией, поскольку данное преступление нередко образует так называемое необходимое соучастие с получением взятки должностным лицом, однако достаточных оснований расценивать это деяние именно как проявление коррупции все-таки нет. Представляется, что в определении «коррупция» не следовало делать акцент и на предоставлении выгоды лицу, незаконно использующему свое должностное положение, другими физическими лицами, поскольку основное значение в данном случае имеет фактическое получение такой выгоды должностным лицом. В этом случае существующее определение позволяет говорить об «успехах» в борьбе с коррупцией и в случаях, когда вместо выявления и пресечения действительных коррупционных деяний (преступлений и правонарушений) со стороны должностных лиц будут устанавливаться факты совершения преступлений против интересов службы в коммерческих и иных организациях (при этом сохраняется прежний порядок осуществления уголовного преследования лиц, преступления которых причинили вред исключительно коммерческой организации, т.е. по ее заявлению или с ее согласия), факты покушения на дачу взятки при отсутствии волеизъявления и намерения должностного лица принять незаконное материальное вознаграждение и т.д.

Анализ определения, изложенного в Федеральном законе «О противодействии коррупции», позволяет говорить о том, что оно не учитывает многообразие проявлений коррупционного поведения, затрагивающего сферы действия различных отраслей права (уголовного, административного, гражданского, трудового, финансового и др.), что обусловливает необходимость комплексного подхода к определению самого явления коррупции. Приводимая в определении характеристика выгод как цели коррупции не соотносится с соответствующими категориями, предусмотренными конкретными нормами Oco- 
бенной части УК РФ (например, ст. 290 УК РФ, где определяется содержание предмета взятки); в действующем Уголовном кодексе Российской Федерации имеется состав злоупотребления должностными полномочиями, а не злоупотребления служебным положением, как это закреплено в ст. 1 Федерального закона. Все это позволяет говорить о том, что анализируемое определение «коррупции» недоработано, оно в известной мере противоречит другим правовым нормам, что может служить препятствием эффективному противодействию коррупции.

В этой связи отметим, что не разделяем мнение тех исследователей, которые пытаются доказать необходимость введения в уголовное право понятия «коррупция».

Представляется, что, являясь по своей сути социальным явлением, коррупция может быть реализована в многочисленных формах, причем необязательно в тех, которые содержат уголовно-правой запрет. Такое широкое понимание данного явления основывается на ином подходе к этимологии самого понятия «коррупция» - подкуп. Мы считаем, что определение коррупции через «corruptio» (подкуп) не совсем точно отражает суть данного понятия. Более правильным представляется иная основа понятия «коррупция», состоящая из латинских слов «correr», т.е. несколько участников обязательственного отношения по поводу единственного предмета, и «rumpere» - ломать, нарушать. В результате мы имеем самостоятельный термин «corrumpere», который предполагает участие в деятельности нескольких лиц (не менее двух), целью которых является «порча», «повреждение нормального процесса управления общества». Очевидно, что понимание коррупции как умышленного нарушения установленного государством процесса управления делами общества подругому расставляет акценты в определении общественной опасности данного явления. Прежде всего, отметим, что порядок управления устанавливается (регулируется) многими отраслями права. В этой связи очевидно, что любой государственный служащий обязан, во-первых, принимать решение исключительно исходя из целей, установленных правом (конституци- ей, законами, другими нормативными актами), и, вовторых, в процессе выполнения своих служебных обязанностей он должен действовать исключительно в рамках (в пределах) установленных соответствующих нормативных актов.

Коррупция начинается тогда, когда цели, установленные в правовых нормах, подменяются субъективными целями должностного лица, направленными на умышленное нарушение установленного правом порядка управления. При этом, на наш взгляд, корыстный интерес (с которым, как правило, связывают те или иные формы коррупционного поведения) может и отсутствовать, поскольку такие деяния могут совершаться как с целью мести, ревности и т.д., так и с целью обогащения третьих лиц.

Сами нарушения установленного государством порядка управления могут иметь различную степень общественной опасности, как и должностные лица, совершающие их.

В этой связи становится очевидным, что к уголовной ответственности можно привлекать лишь тех лиц, степень общественной опасности деяний которых достаточно высокая. Поэтому уголовное право имеет дело с такими формами коррупционного поведения, которые обладают наиболее высокой степенью общественной опасности. Иные формы коррупционного поведения должны пресекаться нормами других отраслей российского законодательства: административного, налогового, таможенного и т.д.

Предлагаемый подход не сводит понятие «коррупция» к её конкретным, наиболее опасным поведенческим проявлениям, поскольку любые попытки заключить данное понятие в жесткие уголовно-правовые рамки приведут к тому, что те или иные формы коррупционного поведения все равно окажутся за пределами уголовного кодекса. По этой же причине нецелесообразно регулирование противодействия коррупции связывать с принятием одного закона.

Представляется, что наиболее эффективно противодействовать коррупции можно лишь используя весь комплекс российского законодательства.

\section{ЛИТЕРАТУРА}

1. Конусы «В» и 2 «С». Урукагины (законодательная Декларация урукагины) / пер. со старошумер. Ю.Б. Гавриловой (по изданию АВWI S. 288-313 Древний Шумер). СПб., 2003. С. 272-273.

2. Каутилья (Чанакья). Артхашастра, или Наука политики. М., 1959. С. 798

3. Библия Сирах. 1, 29, 4, 9. С. 644.

4. Русская правда. Краткая редакция // Российское законодательство Х-XX веков. Законодательство Древней Руси. М., 1984. Т. 1. С. 191.

5. Двинская уставная грамота 1397 г. // Российское законодательство X-XX веков. М., 1984. Т. 2. С. 180.

6. Псковская судная грамота (с комментариями) // Российское законодательство Х-ХХ веков. М., 1984. Т. 1. С. 321.

7. Судебник 1497 г. // Российское законодательство X-XX веков. М., 1984. Т. 2. С. 54

8. Судебник 1550 г. // Российское законодательство X-XX веков. М., 1984. Т. 2. С. 97.

9. Соборное уложение 1649 г. М., 1961. С. 47, 140.

10. Седов П.В. На посуле, как на стуле. Из истории российского чиновничества XVIII в. // Звезда. 1998. № 4. С. 210.

11. Клеандров В.М., Колобов Б.В., Кутьина Г.А., Новицкая Т.Е. Законодательство Петра І. М., 1997. С. 749.

12. Гайдар Е.Т. Государство и эволюция. М., 1995. С. 143.

13. Организованная преступность / под ред. А.И. Долговой, С.В. Дьякова. М., 1989. С. 144

14. Карпец И.И. Преступность: иллюзии и реальность. М., 1992. С. 324-325.

15. Криминология / под ред. А.И. Долговой. М., 1997. С. 501

16. Волженкин Б.В Коррупция. СПб., 1998. С. 10.

17. Обсуждение проблем борьбы с коррупцией. Круглый стол // Государство и право. 1993. № 2. С. 135.

18. Коррупция и борьба с ней / ред. кол.: В.В. Астанин, А.И. Долгова и др. М., 2000. С. 5-6.

19. Государство и право. 1993. № 2. С. 136.

20. Комментарий к УК РФ / под общ. ред. Ю.И. Скуратова и В.М. Лебедева. М., 1997. С. 672

21. Гаухман Л. Коррупция и коррупционное преступление // Законность. 2000. № 4. С. 6 
22. Катаев Н.А. Сердюк Л.В. Коррупция (уголовно-правовой и криминологический аспекты). Уфа, 1995. С. 9.

23. Проект Ф3 «Основы антикоррупционной политики» // Уголовное право. 2001. № 1. С. 8-7.

24. О противодействии коррупции: Федеральный закон от 25 декабря 2008. № 273 Ф3 // Собрание законодательства РФ. 29.12 .2008 . № 52. C. 6228.

Статья представлена научной редакцией «Право» 23 марта 2016 г.

LEGAL COUNTERACTION TO CORRUPTION IN RUSSIA: HISTORY AND CURRENT STATE Tomsk State University Journal, 2016, 405, 178-183. DOI: 10.17223/15617793/405/26

Prozumentov Lev M. Tomsk State University (Tomsk, Russian Federation). E-mail: krim_tsu@mail.ru Keywords: law; behavior; crime; corruption; criminal law; public glasnost.

Formation and development of corruption in Russia has a long history. Thus, the first written mention of the promises of illegal remuneration paid for the governor for the implementation of official authority relates to the late 14th century. In the 15th century, officials carried out their direct duties only for a gift. The first law on the punishment of judges for bribery is found in the Sudebnik [Code of Law] of 1497. The Sudebnik of 1550 considered bribery in more detail. The Sobornoye Ulozhenie [Cathedral Code] of 1649, Peter I's Decree "On Banning Bribes and Promises" of 1708, The Code of Criminal and Correctional Punishments of 1845, The Criminal Law of 1903 contained provisions criminalizing specific forms of corruption. The establishment of the Soviet did not eliminate the problem of corruption. It is natural that two of the first decrees of the new government were the Decree "On Bribery" (May 8, 1918) and the Decree "On Bribery Prevention". The Criminal Codes of the RSFSR in 1922, 1926 and 1960 provided for the responsibility for certain types of corruption: for giving and receiving bribes, abuse of authority and official position, etc. The recent research literature over the last twenty years gives various definitions of corruption. The author emphasises that in terms of crime composition, corruption was initially viewed only as bribery of one person by another, i.e., it was only about bribery in all its forms and varieties. The author underlines that corruption includes not only receiving a bribe, but also other officials' crimes: abuse of office, forgery, etc. With the adoption of Federal Law No. 273-FZ "On Combating Corruption" of December 25, 2008, this notion has been first enshrined in the Russian legislation. However, what do we find here? The fact that is defined as "corruption" is related to particular deeds where it appears. All these deeds come to the following: an unlawful use of an official status by a person despite the legal interests of the society and the state to get benefit for this person or others. In this article, the author analyses this statement and notes that, firstly, the anti-corruption law does not give an unambiguous definition of the notion "corruption" or the area of matter of facts as a basic object of special impact. Secondly, the existing criminal law has no notion "corruption". The author notes that prevention of corruption only by means of criminal law is possible, but the effectiveness of these actions is insignificant. To prevent corruption it is necessary to use norms of other branches of law: administrative law, civil law, labor law, customs law and others.

\section{REFERENCES}

1. Anon. (2003) Konusy “V” i 2 "S”. Urukaginy (zakonodatel'naya Deklaratsiya urukaginy) [The cones "B" and 2 "C". Urukagina (legislative Urukagina Declaration)]. Translated from Old Sumer by Yu.B. Gavrilova. St. Petersburg.

2. Kautilya (Chanakya). (1959) Artkhashastra ili nauka politiki [Arthasastra or the science of politics]. Moscow: USSR AS.

3. Bibliya Sirakh [The Sirach Bible]. 1, 29, 4, 9.

4. Chistyakov, O.I. (ed.) (1984) Russkaya pravda. Kratkaya redaktsiya [Russian truth. A brief revision]. In: Rossiyskoe zakonodatel'stvo X-XX vekov. Zakonodatel'stvo Drevney Rusi [Russian legislation of the 10th-20th centuries. The law of Ancient Rus]. Vol. 1. Moscow: Yuridicheskaya literatura.

5. Chistyakov, O.I. (ed.) (1984) Dvinskaya ustavnaya gramota 1397 g. [Dvina Charter of 1397]. In: Rossiyskoe zakonodatel'stvo X-XX vekov [Russian legislation of the 10th-20th centuries]. Vol. 2. Moscow: Yuridicheskaya literatura.

6. Chistyakov, O.I. (ed.) (1984) Pskovskaya sudnaya gramota (s kommentariyami) [Pskov Judicial Charter (with commentaries)]. In: Rossiyskoe zakonodatel'stvo $X-X X$ vekov [Russian legislation of the 10th-20th centuries]. Vol. 1. Moscow: Yuridicheskaya literatura.

7. Chistyakov, O.I. (ed.) (1984) Sudebnik 1497 g. [Code of Law of 1497]. In: Rossiyskoe zakonodatel'stvo X-XX vekov [Russian legislation of the 10th-20th centuries]. Vol. 2. Moscow: Yuridicheskaya literatura.

8. Chistyakov, O.I. (ed.) (1984) Sudebnik 1550 g. [Code of Law of 1550]. In: Rossiyskoe zakonodatel'stvo X-XX vekov [Russian legislation of the 10th-20th centuries]. Vol. 2. Moscow: Yuridicheskaya literatura.

9. Anon. (1961) Sobornoe ulozhenie $1649 \mathrm{~g}$. [The Council Code of 1649]. Moscow: Moscow State University.

10. Sedov, P.V. (1998) Na posule, kak na stule. Iz istorii rossiyskogo chinovnichestva XVIII v. [On promises like on the chair. From the history of the Russian officialdom of the 18th century]. Zvezda. 4. pp. 210.

11. Kleandrov, V.M. et al. (1997) Zakonodatel'stvo Petra I [Legislation of Peter I]. Moscow: Yuridicheskaya literatura.

12. Gaydar, E.T. (1995) Gosudarstvo i evolyutsiya [State and Evolution]. Moscow: Evraziya.

13. Dolgova, A.I. \& D'yakov, S.V. (eds) (1989) Organizovannaya prestupnost' [Organized crime]. Moscow: Yuridicheskaya literatura.

14. Karpets, I.I. (1992) Prestupnost': illyuzii i real'nost' [Crime: illusion and reality]. Moscow: Rossiyskoe pravo.

15. Dolgova, A.I. (ed.) (1997) Kriminologiya [Criminology]. Moscow: NORMA.

16. Volzhenkin, B.V. (1998) Korruptsiya [Corruption]. St. Petersburg: St. Petersburg Law Institute of the Academy of General Prosecutor's Office.

17. Gosudarstvo i pravo. (1993) Obsuzhdenie problem bor'by s korruptsiey. Kruglyy stol [Discussion of the problems of combating corruption. A Round Table]. Gosudarstvo i pravo - Satet and Law. 2. pp. 135.

18. Astanin, V.V. et al. (eds) (2000) Korruptsiya i bor'ba s ney [Corruption and the fight against it]. Moscow: Rossiyskaya kriminologicheskaya assotsiatsiya.

19. Gosudarstvo i pravo - State and Law. (1993) 2. pp. 136.

20. Skuratov. Yu.I. \& Lebedev, V.M. (eds) (1997) Kommentariy $k$ UK RF [Commentary on the RF Criminal Code]. Moscow: Infra-M-Norma.

21. Gaukhman, L. (2000) Korruptsiya i korruptsionnoe prestuplenie [Corruption and corruption crime]. Zakonnost'. 4. pp. 6.

22. Kataev, N.A. \& Serdyuk, L.V. (1995) Korruptsiya (ugolovno-pravovoy i kriminologicheskiy aspekty) [Corruption (criminal-legal and criminological aspects)]. Ufa: VEGU i UVSh MVD RF.

23. Ugolovnoe pravo. (2001) Proekt FZ "Osnovy antikorruptsionnoy politiki" [Draft Federal Law "Fundamentals of Anti-Corruption Policy"]. Ugolovnoe pravo. 1. pp. 8-7.

24. Russian Federation. (2008) O protivodeystvii korruptsii: Federal’nyy zakon ot 25 dekabrya 2008. № 273 FZ [On Combating Corruption: the Federal Law of December 25, 2008. Federal Law 273]. Sobranie zakonodatel'stva Rossiyskoy Federatsii [Code of Laws of the Russian Federation]. 29 December. 52. pp. 6228 